\title{
Lexical Negative Transfer Analysis and Pedagogic Suggestions of Native Language in Chinese EFL Writing
}

\author{
Lina Yang \\ Foreign Language Department, Xi’an Technological \\ University \\ College of Foreign Languages, Xi'an University of \\ Science and Technology \\ Xi'an, China \\ e-mail: jantonyz@126.com
}

\author{
An-ping Ma \\ Foreign Language Department \\ Xi'an Technological University \\ Xi'an, China
}

\author{
Yan Cao \\ School of Mechatronic Engineering \\ Xi'an Technological University \\ Xi'an, China
}

\begin{abstract}
The objective of the paper is mainly about the analysis of the lexical errors caused by negative transfer of the native language that occur in Chinese EFL writing. Lexical errors in the paper mainly refer to the conceptual or semantic errors in lexis where the subjects use the forms that exist in a target language, but these forms do not represent the meanings they wish to express. The lexical errors mainly involve three types, that is, errors in word choice, errors in derivation and those in collocation. Based on the findings of the research, the three issues are examined in an effort to seek implications for EFL learning and teaching in China.
\end{abstract}

Keywords- lexical transfer; error of word choice; error of derivation; collocation error; pedagogic suggestion.

\section{INTRODUCTION}

The detection of foreign accents in our daily life is an example of the awareness of cross-linguistic influence that is referred to as language transfer. The awareness is also obvious sometimes in opinions that people have about foreign language study.

Odlin [1] offered the working definition of transfer as a basis for his treatment of such phenomena: Transfer is the influence resulting from the similarities and differences between a target language (TL) and any other language that has been previously (and perhaps imperfectly) acquired.

A more behaviorist interpretation of interference was mentioned earlier; and two types were suggested: positive transfer and negative transfer.

\section{A. Positive Transfer}

The best general account of L1 transfer is language transfer, which was written by T. Odlin in 1989. In the book, he believed that the learner's L1 can facilitate L2 learning, and that facilitation is obvious not so much in the total absence of certain errors, but rather in a reduced number of errors.

\section{B. Negative Transfer}

Brown gave the statement that negative transfer occurs when the previous performance disrupts the performance on a second task. It can be known as interference, in that previously learned material-a previous item is incorrectly transferred or incorrectly associated with an item to be learned. It has been common in second language teaching to stress the role of the interfering effects of the native language (NL) on the target language.

Positive language transfer may occur when both the native language and the target language have the same form, thus facilitating learning; while negative language transfer may lead to errors or inappropriate forms in the target language. In a word, similar patterns would be easy to learn because they could be successfully transferred from the native language, and different patterns would cause interference and therefore be difficult to learn. It is not amazing that this process has been chosen because the native language interference is the most immediately noticeable source of errors among second language learners. The saliency of the interference is so strong that some view second language learning as the overcoming of the effect of the native language.

As a result, in the paper, the authors intend to analyze negative Chinese transfer in lexis, the authors try to (a) help students gain insights into similarities and differences between English and Chinese, (b) predict and describe the patterns that will cause difficulty in learning and those that will not cause difficulty, and (c) to provide a more effective pedagogy for English writing teaching

\section{LEXICAL TRANSFER}

Chinese belongs to the Sino-Tibetan family while English belongs to the Indo-European family. Chinese words are written in characters but English words are written by means of alphabetic letters. These two languages hardly share any cognate vocabulary with each other in form. Theoretically, this great distance reduces Chinese learners' 
tendency to commit lexical transfer errors. Research indicates that transference of word meaning and word forms is possible when learners' first and target language share vocabulary cognates. Chinese students frequently transfer the meaning of words or phrases. Lexical errors in the paper mainly involve three types, that is, errors in word choice, errors in derivation and those in collocation.

\section{A. Errors in Word Choice}

The errors relate to word choice are those words semantically unacceptable but grammatically acceptable in the given linguistic context. The main difficulty in choosing a right word lies in the semantic transfer of the mother tongue. The semantic transfer mainly refers to word-forword translation and sometimes Chinese students take it for granted that English words have the same connotation and denotation with their Chinese definitions in a dictionary. Many synonyms in English have similar meanings but different usages. Chinese students always make errors in this respect. Various researches indicate that the errors in word choice are most noticeable, which rank the highest of the total. The authors attempt to find out the possible reasons for the high frequency of the errors in word choice. Some examples are as follows.

(1) They feel alone.

(2) It's uneasy to keep in touch with friends when they are far away.

(3) When they got to the summit of the mountain...

(4) Although she is old, she is full of spirit.

(5) Secondly, we always talk with each other, without any mistake.

"Alone" in the first sentence was used to mean “孤独 的” in Chinese. In English, "alone" is used to describe a thing or a person that is separated from others, and it doesn't suggest unhappiness. The subject of this sentence is "they", so they cannot be alone, but they may feel lonely. "lonely" suggests someone does not want to be unhappy and alone, so "lonely" should be used in this sentence.

The word "uneasy" in the second sentence does not mean "not easy", but means "anxious" or "worried". This is the result of false analogy, that the prefix "un-" expresses the negative meaning of "easy". Thus sentence (2) should be "It is not easy to keep in touch with friends when they are far away." The errors in word choice in sentence (3) and (4) are caused because of the overextension of analogous items in English and Chinese, for example, "spirit" and "summit" may have the meaning of “精神” and “顶峰”, but they are not totally equivalent in connotation.

In example (5), the student probably wants to express that she always talk with her parents, and no misunderstandings are between them. "Mistake" is used to mean wrong opinion or idea, but here she means she and her parents do not fail in understanding each other correctly, so "misunderstanding" should be used instead.

\section{B. Errors in Derivation}

Derivation is the most common word formation in English. It is a way to form a new word by adding a suffix to a word. For example, "-ness" is added to "kind" and a new word "kindness" is formed. There are many derivative morphemes like "-ness" that will change the meaning of the original root or the part of speech. This kind of word formation is not used in Chinese. In fact, the same Chinese word may have different parts of speech in different contexts, but the formation of the word doesn't change. As a result, many Chinese words can be used both as verbs and nouns while the word formation remains the same. Contrastively, the word formations of many English words should be changed to get a verb out of a noun or vice versa. Thus, Chinese students always remember the meaning of an English word while paying little attention to its part of speech. As a result, Chinese students often choose wrong parts of speech of words in writing or speaking in English.

Here are some more examples from the students' compositions.

(6) I think I should value my young (youth).

(7) A health (healthy) body, dear parents, many good friends and...

(8) So we must to be an optimistic (optimist).

(9) Maybe we will loss (lose) the game?

(10) So if you want to success (succeed), you must keep moving forward.

(11) And we have to face the dangerous (danger) of personal information disclosed.

(12) What is happiest (happiness)?

(13) .Please contact us without hesitate (hesitation).

As is mentioned previously, there is not always equivalence in expressions between two languages. Finer distinctions exist in expressing the same concept or object by different peoples. Actually, with the same form of the word, a Chinese word can have several parts of speech in different contexts as can be seen from the following expressions, “安全帽”, “安全到达”, “安全高度”, “经济实 惠”, “国民经济”, “经济规律”. But in English, a prefix or suffix is usually added to the word root according to different parts of speech. So the above Chinese phrases should be "safety helmet”, "arrive safely”, "safe altitude”, "economical”, "national economy”, "economic law" respectively.

The students always only recite the Chinese explanation of the words and fail to learn the words' parts of speech. When writing, students just think of the corresponding English words to express meaning without considering the use constraint of the words. As a result, the students may commit many derivation errors. We can say it's the negative transfer of Chinese.

\section{Errors in Collocation}

It has been agreed that collocation is the most problematic part of a language. Collocation refers to the syntagmatic association between words. If the word that cannot typically precede or follow another word is selected, a collocation error occurs. When writing in English, students always come up with Chinese words and sentences, and then try to find the equivalent of English words without 
distinguishing their semantic difference in a given linguistic context. And it is really no easy job for the Chinese learners to follow the idiomatic or habitual usage of certain words in English collocation. Almost all of them originate from NL interference. In what follows, the authors give a list of examples in the collected samples that show the errors in lexical collocation.

(14) Competition in job-hunting becomes stronger and stronger (Competition of job-hunting becomes more fierce).

(15) In the college I learnt (acquired) knowledge.

(16) We should improve us (our ability) by joining social activities.

(17) The university receives (recruit) more and more students.

(18) After graduation, we have to enter the society to serve for (serve) the people.

(19) I want to marry with (marry) her.

(20) At last, we arrived (arrived in) Beijing.

(21) Mary like to listen (listen to) music.

In example (14), when we say “竞争激烈”, “strong” cannot collocate with competition and the correct words should be "intense", "fierce", "heated" etc. In example (15), when mention “学习知识”, almost all the subjects put it "study" or "learn knowledge", which is caused by word-toword translation of Chinese. The word should be replaced by “gain”, “acquire”, “obtain”, etc. “看” in Chinese is very flexible and can collocate many different words, e.g. “看黑 板”, “看电视”, “看书”, and “看电影”. Their equivalent English expressions are "look at the blackboard”, "watch TV”, “read a book”, and "see a film”. In example (16), we often say “提高自己” by studying something, but in English, "improve" only goes with something instead of somebody, so inferred from the sentence, it can be corrected as "improve our ability to communicate with others". In example (17), the student wants to convey his intended idea “accept or recruit or enroll students", which means to make somebody a member of an organization. Its Chinese meaning is “招收学生”. He misselected the word “receive” that collocates with something when it is in active voice. Chinese students can also make addition or omission mistakes. They add or omit a preposition after a verb such as in example (18), (19), (20), and (21), "serve for the people” (serve the people, 为人民服务), “marry with her” (marry her, 与她结婚), “arrive Beijing” (arrive in Beijing, 到达北京), and “listen music” (listen to music, 听音乐). They ignore the fact that some verbs are intransitive in Chinese but transitive in English or vise versa.

Adherence to the collocation conventions of a foreign language contributes to one's native-likeness, but any violation of the rules of the collocation will causes errors. From above sentences, we find that negative transfer of Chinese, separate storage of lexical information in the mentality, and inappropriate ways of word memorization are the three main possible causes.

\section{Pedagogic Suggestions}

Negative transfer exists in second language acquisition indeed. It influences Chinese learners' English writing in all aspects. The theories on negative transfer have been studied since it was put forward: And great efforts have been made to find out ways to minimize negative transfer. But the result is not so satisfactory because it seemed to be an unavoidable language phenomenon in the process of language acquisition. Therefore, in this section, based on the above study, we put forward the following strategies to help the students avoid lexical negative transfer of Chinese in college English writing.

\section{A. Encouraging Learners to Think in Native Ways}

It is observed in the students' response in the investigation that from time to time they commit negative transfer just because they do not "think" in a native way. By this, we mean if language learners can think in the native way, they will have no chance to transfer their "native thought" into the target language, which results in negative transfer. To put it simply, we should try to make the learners not have the chance to do the word-to-word translation of their native ideas or sentences.

\section{B. Providing Necessary Language Input for the Students}

There are many different views about the role of input in language development. But it has been generally accepted that language input determines the output. And large quantity of L2 input can help regulate learners' habit in formulating their ideas and developing them in idiomatic style, so helps reduce L1 transfer.

\section{Making Contrastive Analysis of Chinese and English}

Odlin pointed out that contrastive analysis is still the most powerful tool to predict possible interference. If learners are fully aware of all the interference potentials, they may avoid making transfer errors. It is necessary for the learners to be conscious about the linguistic differences between Chinese and English. During the course of English teaching, teachers should try to cultivate students' insights and sensitivity towards the differences between Chinese and English through the method of analysis, contrast, and induction.

\section{Building up a good Knowledge of English Vocabulary and Grammar}

We have noticed that L1 transfer causes a lot of errors both at the lexical level and the grammatical level, which greatly damage students' English writing. On the part of teachers, their explanation of new words and phrases and syntactic structures are important for students in college English courses. It is better to provide a situation and associate the new words and phrases with the familiar context of the students' life or with the context of the text. This can help students build an integrated knowledge of English vocabulary and grammar rather than merely 
remembering the semantic equivalents and grammatical rules.

\section{CONCLUSIONS}

In the field of language transfer, researchers in China [2, $3]$ and abroad $[4,5]$ have already done a lot of studies, and work towards a fuller theoretical understanding of when and how learners draw on their L1. The present study is mainly focused on the analysis of the errors caused by negative lexical transfer of native language that occur in Chinese EFL writing. Based on the findings of the paper, three issues are examined in an effort to seek implications for EFL learning and teaching in China. It is found out that L1 transfer correlates with the issues like learners' way of acquiring vocabulary, their perception of linguistic differences between Chinese and English, and their writing strategies. Finally, pedagogical suggestions are worked out on the basis of the investigation and analysis of transfer errors in EFL writing of Chinese learners.

\section{ACKNOWLEDGMENT}

The paper is supported by Shaanxi Major Subject Construction Project and Monograph Fund of Xi'an Technological University.

\section{REFERENCES}

[1] T. Odlin, Language Transfer: Cross-linguistic influence in language learning, London, Cambridge University Press, 1989.

[2] S.F. Liu, "An analysis of negative transfer of Chinese in college English writing," Journal of Guangdong Education Institute, vol. 26, no. 2, pp. 104-107, 2006.

[3] W.J. Zhu, “Transfer found in my Chinese college students' English writings, Language Teaching, no. 10, pp. 153-156, 2007.

[4] S. Gass and L.Selinker, Second Language Acquisition: An Introductory Course, New Jersey, Lawrence Erlbaum Associates, 2001.

[5] S. Krashen, "Newmark's Ignorance Hypothesis and Current Second Language Acquisition Theory,” in Language Transfer in Language. Learning, S. Gass and L. Selinker, Eds. Rowley, MA: Newbury House, 1983. 